\title{
Microbes and cancer: tow killers in one combined action can be prevented?
}

\section{Introduction}

Cancer is a medical term that refers to a wide range of diseases caused by abnormal aggressive cells that grow, multiply, divide and spread in the body. They have the ability to penetrate and destroy healthy cells and tissues in the body. Cancer is one of the leading causes of death in the world. A large number of people die every year from various types of cancer. The risk of cancer is linked to many factors such as age and sex, dietary habits, hormonal, weight, amount of physical activity and sports, smoking, drinking alcohol, exposure to radiation, or chemical contaminants. Although there is a range of cancer diseases that are directly related to infection with various types of bacteria, viruses and parasites. It is estimated that approximately 18 percent of all cancer cases, or nearly one in five, are directly or indirectly associated with infection with a particular type of bacteria. Worldwide studies that estimates $17.8 \%$ of infections associated neoplasms; discloses the percentage ranges from less than $10 \%$ in high-income countries to as high as $25 \%$ in African countries. ${ }^{1,2}$ The most common type of microbial entities causing cancer are viruses. Viruses account for most infection-caused cancers .The viruses involved are Human papillomavirus, Epstein Barr virus, Kaposi's sarcoma-associated herpes virus, human T-lymphotropic virus 1, $\mathrm{HIV}, \mathrm{HBV}$, and $\mathrm{HCV}$ are associated with risks for cervical cancer, anogenital cancer, skin cancer, nasopharyngeal cancer, Burkitt's lymphoma, Hodgkin's lymphoma, Kaposi's sarcoma, adult T-cell leukemia, B-cell lymphoma, liver cancer, and a new polyomaviruses, Merkel cell polyomaviruses identified in 2008. ${ }^{3}$ The most common among these is genital wart virus or Human papillomavirus (HPV), which is the main cause of cervical cancer. In Western developed countries, human papillomavirus and HBV are the most frequently encountered oncogenic DNA viruses. Human papillomavirus is directly mutagenic like Human T-lymphotropic virus, by inducing the viral genes E6 and E7. ${ }^{4}$ This type of cancer, second only to breast cancer, is on the list of the most common cancers among women, and the third after breast cancer and lung cancer. On the list of the most deadly cancers in women, according to international estimates, that cervical cancer kills More than a quarter of a million women a year. In general, cervical cancer is one of the greatest health risks facing women today because of its high prevalence rates and the resulting mortality. It is noted that these prevalence rates and accompanying deaths have increased significantly in the past few decades. ${ }^{5,6}$

The second group of viruses that cause cancer is the group of hepatitis $\mathrm{B}$ viruses (HBV) and $\mathrm{C}$ virus (HCV). $\mathrm{HBV}$, in contrast to $\mathrm{HPV}$, is believed to be indirectly mutagenic by generating reactive oxygen species through chronic inflammation. ${ }^{7-9}$ The risk of liver cancer is estimated to be 200times higher among those with chronic hepatitis B than healthy people. Out of every 200 cases of infection with HBV, the disease causes liver cancer in one of them. This increases with the virus (C) infection to one cancer of every 45 cases. Liver cancer is more likely to develop if the liver is with cirrhosis, whether due to viral infection or another cause of cirrhosis, such as excessive drinking. Because viral hepatitis is a widespread disease, with 240million people currently suffering from chronic infection with $\mathrm{B}$ and 150million others suffering from chronic infection with
Volume 4 Issue 3 - 2017

\author{
Chateen I Ali Pambuk \\ Tikrit University, Iraq
}

Correspondence: Chateen I Ali Pambuk, College of Dentistry, Tikrit University, Iraq, Email dr.chatin2@yahoo.com

Received: June 26, 2017 | Published: July 13, 2017

$\mathrm{C}$ virus. As liver cancer is a fatal disease in the vast majority of cases, one of the major causes of cancer deaths, especially in East Asia and sub-Saharan Africa. It is worth mentioning that HCV (like HBV) is believed to produce oxidative stress in infected cells and thus to act indirectly through chronic inflammation. ${ }^{10,11}$ The third group of common viruses that cause cancer is the group of herpes viruses. A number of viruses have been identified to be associated with carcinogenesis, and these include lymphotropic Herpesviruses, namely EBV and Kaposi's sarcoma-associated herpes virus [KSHV, also known as human herpes virus type 8 (HHV8)]. ${ }^{12}$ Some of which cause a type of leukemia, lymphoma, throat cancer, a specific type of cancer, and may be, with doubts, a prostate cancer. Both $\gamma$ subfamilies of Herpesviruses are tumorigenic agents. HHV-8 is mainly the etiologic agent associated with Kaposi's sarcoma, a cancer most frequently diagnosed in patients with AIDS. ${ }^{13}$ EBV is mainly associated with nasopharyngeal carcinoma, as well as with Burkett, Hodgkin's, immune-suppression-related non-Hodgkin, and extra nodal NK/T-cell lymphomas. ${ }^{14}$ These viruses interact in some way with the AIDS virus (HIV), which does not cause cancer directly, but as a result of destroying the immune system, it makes the body unable to control or control other viruses that cause cancer directly. Recent studies suggest the oncogenicity of herpes and PyVs in thyroid cancer remains controversial. ${ }^{15}$

The relationship between cancer and infectious bacteria is not limited to viruses, but also to bacteria. The most common example of this relationship is bacteria that cause chronic inflammation and ulcers in the stomach wall, ending with stomach cancer. The bacteria involved in gastritis Helicobacter pylori, may also be involved, acting as cofactors and/or carcinogens Although very few people with these bacteria develop into stomach cancer, due to widespread infection among large numbers of people, it is believed to be the leading cause of stomach cancer ${ }^{16}$ Parasites also play a role in increasing the risk of cancer, specifically the parasite responsible for schistosomiasis. The inflammation caused by schistosomiasis is caused by urinary bladder cancer, rectal and anal cancer in Asian species of the disease, and liver worms cause bile duct cancer. It is also believed that there is a link between malaria parasitic infection in African countries and one type of leukemia. ${ }^{17}$

It is worth mentioning that the mechanisms by which infectious agents promote cancer are becoming increasingly evident. Infectionrelated inflammation is the major risk factor for cancer, and almost all viruses linked to cancer have been shown to activate the inflammatory 
marker, NF-kB. ${ }^{18}$ Similarly, components of Helicobacter pylori have been shown to activate NF-kB. ${ }^{19}$ Thus, agents that can block chronic inflammation should be effective in treating these conditions.

This list shows the strength of the link between infectious diseases and cancer, especially viral infections, which are second on the list of causes of cancer, which is preceded by this list only the use of tobacco products. This opens the way for the prevention of a significant proportion of cancer diseases through the use of medical vaccinations, as is the case with cervical cancer virus, and hepatitis B virus, which is currently one of the most effective ways to prevent cancer. Similarly, the vast majority of cases of stomach cancer can also be prevented through the use of antibiotics that eliminate the bacteria that cause stomach ulcers, the use of anthelmintic to eliminate schistosomiasis and liver worms, and the prevention of bladder cancer and liver cancer. So the tow remarkable human first killers in one combined action can be prevented a treated in a simple way by employing an intensified strategies of eradication of infectious agents by medications.

\section{Acknowledgements}

None.

\section{Conflict of interest}

The author declares no conflict of interest.

\section{References}

1. Pisani P, Parkin DM, Muñoz N, et al. Cancer and infection: estimates of the attributable fraction in 1990. Cancer Epidemiol Biomarkers Prev. 1997;6(6):387-400.

2. Parkin DM. The global health burden of infection-associated cancers in the year 2002. Int J Cancer. 2006;118(12):3030-3044.

3. Anand P, Kunnumakkara AB, Sundaram C, et al. Cancer is a Preventable Disease that Requires Major Lifestyle Changes. Pharm Res. 2008;25(9):2097-2116.

4. Song S, Pitot HC, Lambert PF. The human papillomavirus type 16 E6 gene alone is sufficient to induce carcinomas in transgenic animals. $J$ Virol. 1999;73(7):5887-5893.

5. World Health Organization (WHO). Initiative for Vaccine Research, authors. Human Papilloma Infection and Cervical Cancer. Switzerland: WHO; 2008.
6. Nour NM. An Introduction to Global Women's Health. Reviews in Obstetrics and Gynecology. 2008;1(1):33-37.

7. Blumberg BS, Larouzé B, London WT, et al. The relation of infection with the hepatitis B agent to primary hepatic carcinoma. Am J Pathol. 1975;81(3):669-682.

8. Hagen TM, Huang S, Curnutte J, et al. Extensive oxidative DNA damage in hepatocytes of transgenic mice with chronic active hepatitis destined to develop hepatocellular carcinoma. Proc Natl Acad Sci U S A. 1994;91(6):12808-12812.

9. Jackson AL, Loeb LA. The contribution of endogenous sources of DNA damage to the multiple mutations in cancer. Mutat Res. 2001;477(12):7-21.

10. De Maria N, Colantoni A, Fagiuoli S, et al. Association between reactive oxygen species and disease activity in chronic hepatitis C. Free Radic Biol Med. 1996;21(3):291-295.

11. Koike K, Tsutsumi T, Fujie H, et al. Molecular mechanism of viral hepatocarcinogenesis. Oncology. 2002;62(Suppl 1):29-37.

12. Stamatiou DP, Derdas SP, Zoras OL, et al. Herpes and polyoma family viruses in thyroid cancer. Oncol Lett. 2016;11(3):1635-1644.

13. Boshoff C, Weiss R. AIDS-related malignancies. Nat Rev Cancer. 2002;2(5):373-382.

14. Sarid R, Gao SJ. Viruses and human cancer: From detection to causality. Cancer Lett. 2011;305:218-227.

15. Almeida JF, Campos AH, Marcello MA, et al. Investigation on the association between thyroid tumorigeneses and herpesviruses. $J$ Endocrinol Invest. 2017;40(8):823-829.

16. Ishaq S, Nunn L. Helicobacter pylori and gastric cancer: a state of the art review. Gastroenterology and Hepatology From Bed to Bench. 2015;8(Supp11):S6-S14.

17. Belpomme D, Irigaray P, Hardell L, et al. The multitude and diversity of environmental carcinogens. Environ Res. 2007;105(3):414-429.

18. Guan YS, He Q, Wang MQ, et al. Nuclear factor kappa B and hepatitis viruses. Expert Opin Ther Targets. 2008;12(3):265-280.

19. Takayama S, Takahashi H, Matsuo Y, et al. Effects of Helicobacter pylori infection on human pancreatic cancer cell line. Hepatogastroenterology. 2007;54(80):2387-2391. 